\title{
Origin of Chemically Ordered Atomic Laminates (i-MAX): Expanding the Elemental Space by a Theoretical/Experimental Approach
}

Martin Dahlqvist, Andrejs Petruhins, J un Lu, Lars Hultman and J ohanna Rosén

The self-archived postprint version of this journal article is available at Linköping University Institutional Repository (DiVA):

http:/ / urn.kb.se/ resolve?urn=urn:nbn:se:liu:diva- 151512

N.B.: When citing this work, cite the original publication.

Dahlqvist, M., Petruhins, A., Lu, J., Hultman, L., Rosén, J., (2018), Origin of Chemically Ordered Atomic Laminates (i-MAX): Expanding the Elemental Space by a Theoretical/Experimental Approach, ACS Nano, 12(8), 7761-7770. https:// doi.org/ 10.1021/ acsnano.8b01774

Original publication available at:

https:// doi.org/ 10.1021/acsnano.8b01774

Copyright: American Chemical Society

http:/ / pubs.acs.org/ 


\title{
The Origin of Chemically Ordered Atomic
}

\section{Laminates ( $i$-MAX); Expanding the Elemental Space by a Theoretical/Experimental Approach}

\author{
Martin Dahlqvist*, Andrejs Petruhins, Jun Lu, Lars Hultman, Johanna Rosen*
}

Thin Film Physics, Department of Physics, Chemistry and Biology (IFM), Linköping University, SE-581 83 Linköping, Sweden

* corresponding authors

martin.dahlqvist@liu.se,johanna.rosen@liu.se

KEYWORDS: DFT, materials synthesis. $i$-MAX, chemical order, atomic laminate, HR-STEM 


\section{ABSTRACT}

With increased chemical diversity and structural complexity comes the opportunities for innovative materials possessing advantageous properties. Herein, we combine predictive firstprinciples calculations with experimental synthesis, to explore the origin of formation of the atomically laminated $i$-MAX phases. By probing $\left(\mathrm{Mo}_{2 / 3} M_{1 / 3}^{2}\right)_{2} A \mathrm{C}$ (where $M^{2}=\mathrm{Sc}, \mathrm{Y}$, and $A=$ Al, Ga, In, Si, Ge, In), we predict seven stable $i$-MAX phases, five of which should have a retained stability at high temperatures. $\left(\mathrm{Mo}_{2 / 3} \mathrm{Sc}_{1 / 3}\right)_{2} \mathrm{GaC}$ and $\left(\mathrm{Mo}_{2 / 3} \mathrm{Y}_{1 / 3}\right)_{2} \mathrm{GaC}$ were experimentally verified, displaying the characteristic in-plane chemical order of $\mathrm{Mo}$ and $\mathrm{Sc} / \mathrm{Y}$ and Kagomé-like ordering of the $A$-element. We suggest that the formation of $i$-MAX phases requires a significantly different size of the two metals, and a preferable smaller size of the $A$ element. Furthermore, the population of antibonding orbitals should be minimized, which for the metals herein (Mo and Sc/Y) means that $A$-elements from Group 13 (Al, Ga, In) are favored over Group 14 (Si, Ge, Sn). Using these guidelines, we foresee a widening of elemental space for the family of $i$-MAX phases and expect more phases to be synthesized, which will realize useful properties. Furthermore, based on $i$-MAX phases as parent materials for 2D MXenes, we also expect that the range of MXene compositions will be expanded. 


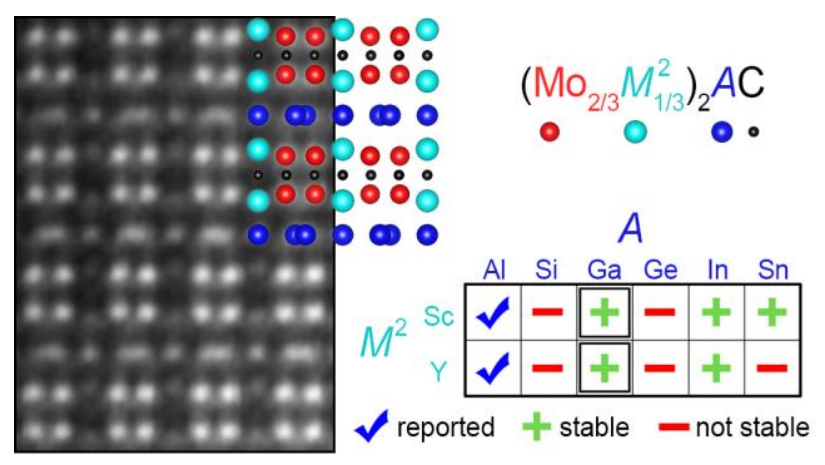

TOC figure. 
The opportunities for discovery of pioneering compounds with modern day computational tools are vast, with numerous examples of exotic materials properties proposed using theoretical calculations, such as storage capacity in metal-organic frameworks and magnetic MXenes. ${ }^{1,2}$ However, prediction of promising properties of metastable or even unstable materials is largely irrelevant if the hypothetical compound can not be experimentally realized. A useful approach to avoid such scenario is to employ first-principles calculations, to investigate the materials stability to serve as experimental guidance, but also for an improved understanding of why certain elemental combination are favored and others not. Stability predictions have been proven successful for a vast number of material families such as half-Heusler alloys, ${ }^{3}$ oxynitrides, ${ }^{4}$ and so called MAX phases. ${ }^{5,6}$

The MAX phases, of the general formula $M_{n+1} A X_{n}(n=1-3)$, are a family of atomically layered ceramics that consist of $M_{n+1} X_{n}$ sheets based on an early transition metal $M$ and $\mathrm{C}$ and/or $\mathrm{N}$ as $X\left(e . g\right.$., $\mathrm{Ti}_{2} \mathrm{C}$ and $\left.\mathrm{Nb}_{2} \mathrm{C}\right)$ sandwiched in between one atom thick $A$-layers ( $A$-group elements $\mathrm{Si}, \mathrm{Al}, \mathrm{Ga}$, etc. $).^{7,8}$ To date $\sim 70$ ternary MAX phases have been synthesized with $\mathrm{Zr}_{2} \mathrm{AlC}$ and $\mathrm{Mn}_{2} \mathrm{GaC}$ being among the latest ternary additions. ${ }^{5,9-11}$ The large interest in MAX phases stems from their combination of metallic and ceramic attributes, ${ }^{8,12}$ and properties such as reversible deformation, ${ }^{13}$ oxidation resistance and self-healing characteristics, ${ }^{14,}{ }^{15}$ and magnetism. ${ }^{5,10,16-}$ 18 The main importance, however, is likely as parent material for its two-dimensional (2D) derivative, MXene, realized from selective etching of the $A$-element. ${ }^{19,20}$ Even though MXenes are a comparatively young family of 2D materials, it has shown high promise for, e.g., use as electrodes in batteries and supercapacitors, ${ }^{21}$ and electromagnetic interference shielding. ${ }^{22}$

With the addition of a fourth element to the traditional ternary MAX phases comes the possibility to tune or alter properties, ${ }^{23,24}$ and even add additional properties. ${ }^{25,26}$ Alloying can be made on either the $M, A$, or $X$ sublattice, allowing a rich variation of compositions, ${ }^{27-33}$ also including elements beyond those traditionally used in MAX phases. ${ }^{30,34,35}$ To date, alloying 
through solid solutions is the primary route investigated. However, attaining an exact $a$ priori decided composition for such material may be challenging. This is opposed to systems where the underlying crystal lattice or symmetry governs the stoichiometry. The first example of a chemically ordered MAX phase was the $o$-MAX phases $\mathrm{Cr}_{2} \mathrm{TiAlC}_{2}$, followed by $\mathrm{Mo}_{2} \mathrm{TiAlC}_{2}$, and $\mathrm{Mo}_{2} \mathrm{ScAlC}_{2}$, defined by out-of-plane ordering through alternating $M$-layers based on one $M$-element only. ${ }^{36-38}$ More recently, a family of chemically ordered MAX-phase related materials was discovered, with in-plane chemical ordering, hence coined $i$-MAX. The first examples of such phases were $\left(\mathrm{Mo}_{2 / 3} \mathrm{Sc}_{1 / 3}\right)_{2} \mathrm{AlC}, \quad\left(\mathrm{Mo}_{2 / 3} \mathrm{Y}_{1 / 3}\right)_{2} \mathrm{AlC}, \quad\left(\mathrm{V}_{2 / 3} \mathrm{Zr}_{1 / 3}\right)_{2} \mathrm{AlC}$, $\left(\mathrm{Cr}_{2 / 3} \mathrm{Sc}_{1 / 3}\right)_{2} \mathrm{AlC}$ and $\left(\mathrm{Cr}_{2 / 3} \mathrm{Y}_{1 / 3}\right)_{2} \mathrm{AlC},{ }^{39-41}$ described by space group $C / 2 c$ (\#15) and $\mathrm{Cmcm}(\# 63)$, and with characteristics such as the minority $M$-element (Sc, Y, and $\mathrm{Zr}$ ) extending out from the $M$-layer towards the $A$-layer, in turn displaying Kagomé-like ordering. As important, the discovery of $i$-MAX phases have realized a type of MXenes with ordered vacancies through selective etching of the $A$-layer as well as the minority $M$-element. ${ }^{39}$ These MXenes have already shown great promise for energy storage applications.

The recent discovery of $i$-MAX phases motivates exploration of their origin, to increase the fundamental understanding of the principles underlying their formation, and to allow prediction and synthesis of further unexplored phases. In the present work, we use $\left(\mathrm{Mo}_{2 / 3} \mathrm{Sc}_{1 / 3}\right)_{2} A \mathrm{C}$ and $\left(\mathrm{Mo}_{2 / 3} \mathrm{Y}_{1 / 3}\right)_{2} A \mathrm{C}$ as model systems to explore the possibilities of extending the $i$-MAX phases beyond $A=$ Al. Employing predictive first-principles stability calculations and probing $A$ from Group 13 (Al, Ga, In) and 14 (Si, Ge, Sn), we evaluate materials stability and the potential for chemically ordered/disordered structures at typical bulk synthesis temperatures. We identify five $i$-MAX phases that are both thermodynamically stable and ordered at and below $1773 \mathrm{~K}$; $\left(\mathrm{Mo}_{2 / 3} \mathrm{Sc}_{1 / 3}\right)_{2} \mathrm{AlC},{ }^{39}, \quad 40 \quad\left(\mathrm{Mo}_{2 / 3} \mathrm{Sc}_{1 / 3}\right)_{2} \mathrm{GaC}, \quad\left(\mathrm{Mo}_{2 / 3} \mathrm{Y}_{1 / 3}\right)_{2} \mathrm{AlC},{ }^{40} \quad\left(\mathrm{Mo}_{2 / 3} \mathrm{Y}_{1 / 3}\right)_{2} \mathrm{GaC}, \quad$ and $\left(\mathrm{Mo}_{2 / 3} \mathrm{Y}_{1 / 3}\right)_{2} \mathrm{InC}$. Bulk synthesis of $\left(\mathrm{Mo}_{2 / 3} \mathrm{Sc}_{1 / 3}\right)_{2} \mathrm{GaC}$ and $\left(\mathrm{Mo}_{2 / 3} \mathrm{Y}_{1 / 3}\right)_{2} \mathrm{GaC}$ was attempted, and their realization verified through X-ray diffraction (XRD) and scanning transmission electron 
microscopy (STEM). Our results demonstrate that expansion of various combinations of $M$ and $A$ within this family of $i$-MAX phases is possible, and a set of guidelines allowing explanation and prediction of their formation is suggested.

\section{RESULTS AND DISCUSSION}

Theoretical stability predictions. To evaluate the materials phase stability, we compare the energy of the $i$-MAX phase to an identified set of most competing phases (equilibrium simplex) in terms of the formation enthalpy $\Delta H_{c p}$, see Methods. This approach has previously been used for numerous predictions of MAX phases and related materials. $6,33,40$ For $\Delta H_{c p}<0$ the compound is considered stable, while for $\Delta H_{c p}>0$ it is considered to be not stable or at best metastable. Figure 1a shows the calculated stability of 12 different $i$-MAX compositions; $\left(\mathrm{Mo}_{2 / 3} \mathrm{Sc}_{1 / 3}\right)_{2} A \mathrm{C}$ and $\left(\mathrm{Mo}_{2 / 3} \mathrm{Y}_{1 / 3}\right)_{2} A \mathrm{C}$ with $A=\mathrm{Al}, \mathrm{Ga}, \mathrm{In}, \mathrm{Si}, \mathrm{Ge}$, and In. Identified equilibrium simplex for each $i$-MAX phase is found in Table S1. Out of these, seven are found to be thermodynamically stable with a negative formation enthalpy $\Delta H_{\mathrm{cp}}$, including the recently reported Al-based $i$-MAX phases $\left(\mathrm{Mo}_{2 / 3} \mathrm{Sc}_{1 / 3}\right)_{2} \mathrm{AlC}$ and $\left(\mathrm{Mo}_{2 / 3} \mathrm{Y}_{1 / 3}\right)_{2} \mathrm{AlC}^{39,} 40$ These are also dynamically stable as seen by the calculated phonon dispersion in Figure S1 and S2.

It was previously shown that $i$-MAX can have several different, closely related, crystal structures being effectively degenerated in energy. ${ }^{39}$ We therefore consider both orthorhombic $\mathrm{Cmcm}$ and monoclinic $\mathrm{C} 2 / \mathrm{c}$ symmetry in our comparison and in all cases find these to be within $2 \mathrm{meV} /$ atom, i.e., effectively degenerate.

The use of $0 \mathrm{~K}$ calculations for prediction of hypothetical MAX phase compounds is motivated by the shown mutual cancellation of the temperature dependent energy terms, vibrational and electronic, to the Gibbs free energy which is then primarily governed by the 0 K energy terms. ${ }^{42}$ For alloys, however, with disorder of $M^{1}$ and $M^{2}$ on the $M$-lattice in $M_{2} A X$, the configurational entropy will make a significant difference and decrease the free energy with 
increasing temperature. Keeping the composition fixed and comparing the energy between inplane chemical order ( $i$-MAX) and a disordered distribution on the $M$ lattice (assuming the ordinary MAX phase structure), we can thus estimate above which temperature the disordered structure is energetically favorable due to configurational entropy, see details in Methods. This disorder temperature $T_{\text {disorder }}$ is then compared with typical bulk synthesis temperatures of $\sim 1500{ }^{\circ} \mathrm{C}(1773 \mathrm{~K})$, as shown in Figure $1 \mathrm{~b}$. Nine $i$-MAX phases have $T_{\text {disorder }}>1773 \mathrm{~K}$. Out of the seven phases that fulfil $\Delta H_{\mathrm{cp}}<0$ (Figure 1a) we identify five i-MAX phases that also have $T_{\text {disorder }}>1773 \mathrm{~K} ;\left(\mathrm{Mo}_{2 / 3} \mathrm{Sc}_{1 / 3}\right)_{2} \mathrm{AlC},\left(\mathrm{Mo}_{2 / 3} \mathrm{Sc}_{1 / 3}\right)_{2} \mathrm{GaC},\left(\mathrm{Mo}_{2 / 3} \mathrm{Y}_{1 / 3}\right)_{2} \mathrm{AlC},\left(\mathrm{Mo}_{2 / 3} \mathrm{Y}_{1 / 3}\right)_{2} \mathrm{GaC}$, and $\left(\mathrm{Mo}_{2 / 3} \mathrm{Y}_{1 / 3}\right)_{2} \mathrm{InC}$. However, for at least $\left(\mathrm{Mo}_{2 / 3} \mathrm{Sc}_{1 / 3}\right)_{2} \mathrm{InC}$ and $\left(\mathrm{Mo}_{2 / 3} \mathrm{Sc}_{1 / 3}\right)_{2} \mathrm{SnC}$, with $\Delta H_{\mathrm{cp}}<0$, the configurational entropy may decrease the free energy for the solid solutions and make the disordered distribution energetically favorable and likely to be realized during synthesis. It should be noted that we find largest $T_{\text {disorder }}$ for A-elements from Period 3 (Al, Si) and then decreasing when going to Period 4 (Ga, Ge) and 5 (Sn, In).

Analyzing the data, we can identify two trends for $M^{2}=\mathrm{Y}$; (i) a steady increase in $\Delta H_{c p}$ when going from A-elements from Period $3(\mathrm{Al}, \mathrm{Si})$ to $4(\mathrm{Ga}, \mathrm{Ge})$ and then to $5(\mathrm{In}, \mathrm{Sn})$ and (ii) within each Period of A-elements those from Group 13 (Al, Ga, In) always have lower $\Delta H_{c p}$ as compared to Group 14 (Si, Ge, Sn). For $M^{2}=\mathrm{Sc}$, only the latter trend holds within each Period of A-elements and $\Delta H_{c p}$ decreases in Group 14 (Si, Ge, Sn) when going from Period 3 (Si) to $5(\mathrm{Sn})$. Even though the trends give a measure of the relative stability of the different phases, the values of $\Delta H_{\mathrm{cp}}$ are dependent on the presence of competing phases in each system, and the stability of those phases. For Si-based systems, for example, stable silicide ternaries are identified as most competing phases which will push $\Delta H_{\mathrm{cp}}$ to higher values as compared to, e.g., the Mo-Y-Ge-C system where binaries are among the most competing phases. A detailed evaluation of the trends is therefore not relevant. 

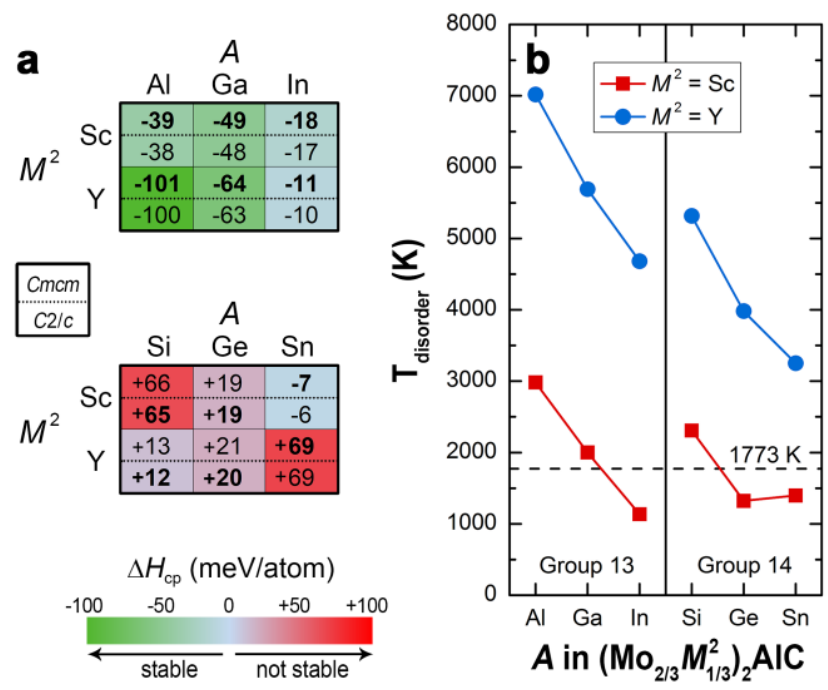

Figure 1. (a) Calculated formation enthalpy $\Delta \mathrm{H}_{\mathrm{cp}}$ for in-plane chemically-ordered $\left(\mathrm{Mo}_{2 / 3} \mathrm{Sc}_{1 / 3}\right)_{2} A \mathrm{C}$ and $\left(\mathrm{Mo}_{2 / 3} \mathrm{Y}_{1 / 3}\right)_{2} A \mathrm{C}$ in orthorhombic $C m c m$ and monoclinic $C 2 / c$ symmetry, where green indicate stable and red not stable candidates. Numbers in bold indicate the structure of lowest energy. (b) Estimated temperature above which the disordered structure is energetically favorable compared to the chemically ordered structure, $T_{\text {disorder}}$, for $\left(\mathrm{Mo}_{2 / 3} \mathrm{Sc}_{1 / 3}\right)_{2} A \mathrm{C}$ (red squares) and $\left(\mathrm{Mo}_{2 / 3} \mathrm{Y}_{1 / 3}\right)_{2} A \mathrm{C}$ (blue circles) as function of A-group element. The dashed horizontal line in (b) represents a typical bulk synthesis temperature of $1773 \mathrm{~K}$.

Experimental realization and structural characterization. Material synthesis was attempted for compounds not yet reported, but predicted stable with $\Delta H_{\mathrm{cp}}<-25 \mathrm{meV} / \mathrm{atom}$, and with a disorder temperature larger than typical synthesis conditions ( $\left.T_{\text {disorder }}>1773 \mathrm{~K}\right)$, i.e., $\left(\mathrm{Mo}_{2 / 3} \mathrm{Sc}_{1 / 3}\right)_{2} \mathrm{GaC}$ and $\left(\mathrm{Mo}_{2 / 3} \mathrm{Y}_{1 / 3}\right)_{2} \mathrm{GaC}$. Our predictions were indeed experimentally verified upon optimized synthesis conditions. XRD of $\left(\mathrm{Mo}_{2 / 3} \mathrm{Sc}_{1 / 3}\right)_{2} \mathrm{GaC}$ and $\left(\mathrm{Mo}_{2 / 3} \mathrm{Y}_{1 / 3}\right)_{2} \mathrm{GaC}$ samples are shown in Figure 2. Corresponding simulated patterns are based on relaxed $i$-MAX structures with orthorhombic $\mathrm{Cmcm}$ symmetry. In passing, we note that the PBE parameterized approximation used, in general, and in particular for $i$-MAX phases, tend to underestimate the bond strength, resulting in XRD peaks shifted to lower $2 \theta$ angles. ${ }^{40}$ The characteristic in-plane (110) peak of an $i$-MAX phase is clearly seen for both compounds, a peak which is not present 
for traditional $M_{2} A X$ phases. Peaks originating from the $i$-MAX phase are marked with blue stars in the diffractograms. Unmarked peaks correspond to minority phases $\mathrm{Mo}_{2} \mathrm{C}, \mathrm{C}$ (graphite), $\mathrm{Sc}_{2} \mathrm{O}_{3}, \mathrm{Sc}_{2} \mathrm{OC}$ and $\mathrm{ScGa}_{3}$ in Figure $2 \mathrm{a}$, and $\mathrm{Mo}_{2} \mathrm{C}, \mathrm{C}$ (graphite), $\mathrm{Y}_{2} \mathrm{O}_{3}$ in Figure $2 \mathrm{c}$.
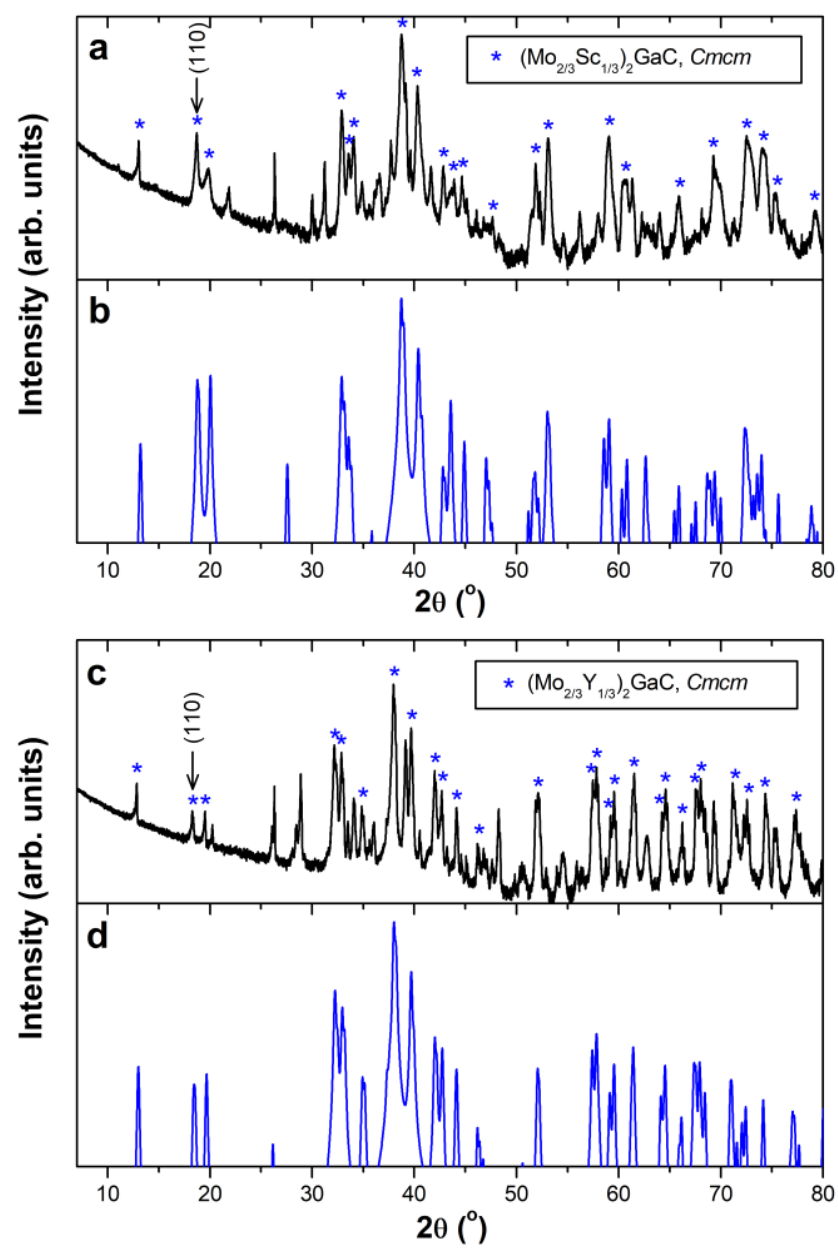

Figure 2. Measured and simulated XRD of atomic laminate phases with in-plane chemical ordering. (a,c) Measured XRD data for $\left(\mathrm{Mo}_{2 / 3} \mathrm{Sc}_{1 / 3}\right)_{2} \mathrm{GaC}$ and $\left(\mathrm{Mo}_{2 / 3} \mathrm{Y}_{1 / 3}\right)_{2} \mathrm{GaC} i$-MAX phases and $(b, d)$ corresponding simulated patterns. The simulations are based on relaxed structures with orthorhombic $\mathrm{Cmcm}$ symmetry. The match between measured and calculated peaks are indexed by blue stars *. The typical in-plane (110) peak of an $i$-MAX phase is indicated by an arrow.

In-plane STEM images of $\left.\mathrm{Mo}_{2 / 3} \mathrm{Sc}_{1 / 3}\right)_{2} \mathrm{GaC}$ and $\left(\mathrm{Mo}_{2 / 3} \mathrm{Y}_{1 / 3}\right)_{2} \mathrm{GaC}$ in Figure 3 and 4, respectively, further confirm the formation of an in-plane chemically-ordered material. The right-hand side of Figure 3 and 4 depicts schematic representations of the orthorhombic 
structure of space group $\mathrm{Cmcm}$ along selected zone axis. Analysis of STEM images from multiple grains of both compounds in all cases show the $\mathrm{Cmcm}$ structure. When viewed along the [010] and [110] zone axis the in-plane order is apparent within the $M_{2} \mathrm{C}$ layers, where the brightest spots correspond to Mo and the less bright to Sc (Figure 3) and Y (Figure 4). Carbon is too light to be visible. Between the $M_{2} \mathrm{C}$ layers we find the A-layer, showing spots of different contrast and spatial distribution. The origin thereof, Kagomé-like ordering, will be elaborated below. Along the [100] zone axis, Mo and Sc or Y are superimposed resulting in an average contrast strongly resembling a traditional 211 MAX phase. A summary of structural data for the $\mathrm{Cmcm}$ structure of $\left(\mathrm{Mo}_{2 / 3} \mathrm{Sc}_{1 / 3}\right)_{2} \mathrm{GaC}$ and $\left(\mathrm{Mo}_{2 / 3} \mathrm{Y}_{1 / 3}\right)_{2} \mathrm{GaC}$ is given in Table. 1 . The finding of $i$-MAX phases with $\mathrm{Cmcm}$ structure is different to previously synthesized ( $\left.\mathrm{Mo}_{2 / 3} \mathrm{Sc}_{1 / 3}\right)_{2} \mathrm{AlC}$, $\left(\mathrm{Mo}_{2 / 3} \mathrm{Y}_{1 / 3}\right)_{2} \mathrm{AlC},\left(\mathrm{V}_{2 / 3} \mathrm{Zr}_{1 / 3}\right)_{2} \mathrm{AlC}$, and $\left(\mathrm{Cr}_{2 / 3} \mathrm{Sc}_{1 / 3}\right)_{2} \mathrm{AlC}$ which all were found with $C 2 / c$ as the majority structure. ${ }^{39,40,43}$
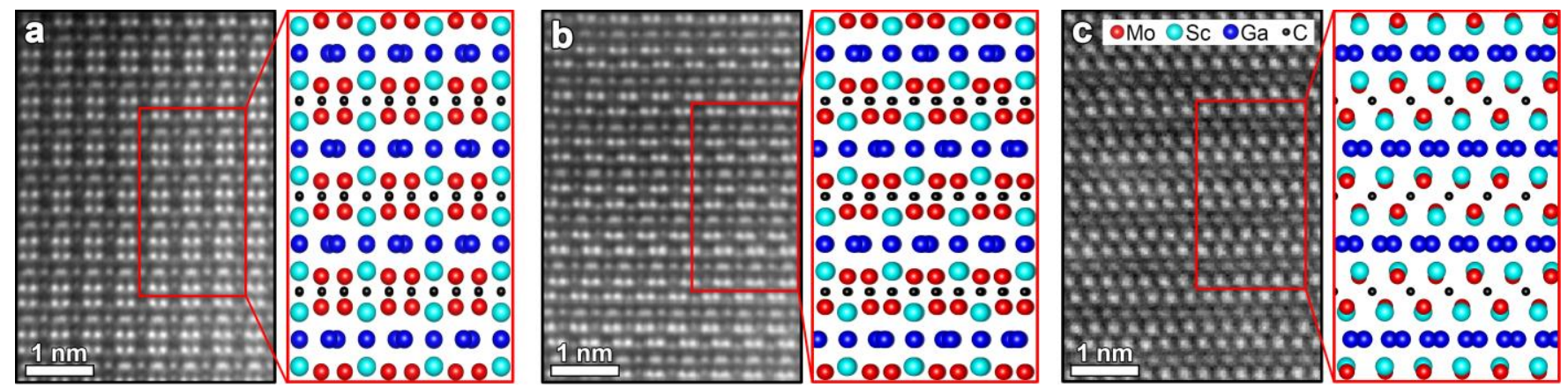

Figure 3. HRSTEM images and schematic representation of the in-plane chemical ordering of

(a) $\left(\mathrm{Mo}_{2} / 3 \mathrm{Sc}_{1 / 3}\right)_{2} \mathrm{GaC}$ along the (a) [010], (b) [110], and (c) [100] zone axes. Schematic representation represents the corresponding atomic arrangement based on an orthorhombic structure of space group $\mathrm{Cmcm}$. 

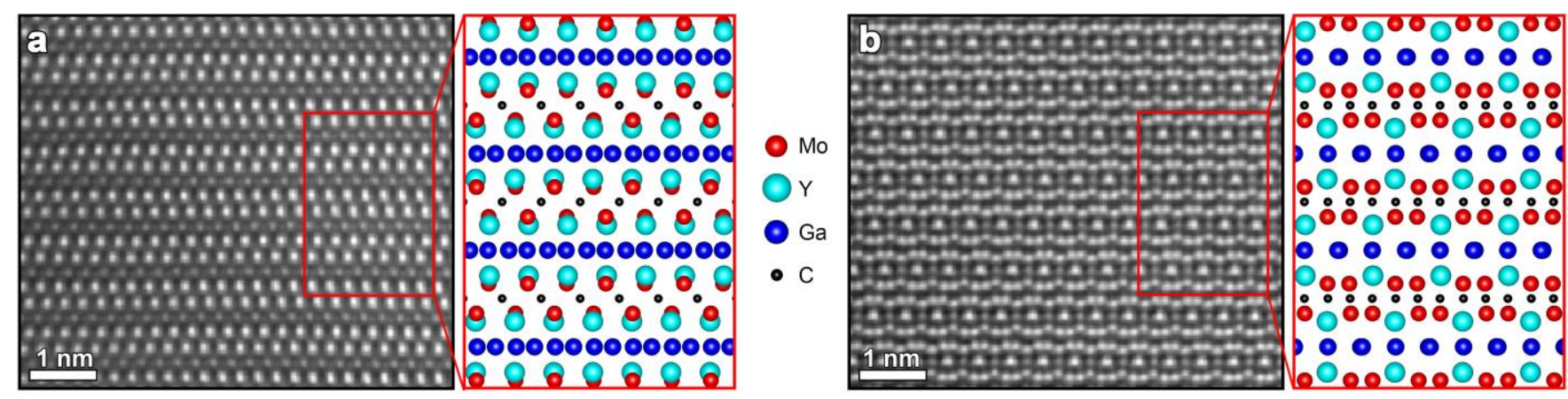

Figure 4. HRSTEM images and schematic representation of the in-plane chemical ordering of

$\left(\mathrm{Mo}_{2 / 3} \mathrm{Y}_{1 / 3}\right)_{2} \mathrm{GaC}$ along the (a) [100] and (b) [110] zone axes. Schematic representation represents the corresponding atomic arrangement based on an orthorhombic structure of space group $\mathrm{Cmcm}$.

Table 1. Calculated crystallographic data for orthorhombic $\mathrm{Cmcm}\left(\mathrm{Mo}_{2 / 3} \mathrm{Sc}_{1 / 3}\right)_{2} \mathrm{GaC}$ and $\left(\mathrm{Mo}_{2 / 3} \mathrm{Y}_{1 / 3}\right)_{2} \mathrm{GaC}$ structure using the GGA-PBE exchange-correlation functional with Wyckoff positions given for each unique crystallographic site.

\begin{tabular}{|c|c|c|c|c|c|c|c|c|}
\hline \multirow{2}{*}{$\begin{array}{l}\text { Compound } \\
\left(\mathrm{Mo}_{2 / 3} \mathrm{Sc}_{1 / 3}\right)_{2} \mathrm{GaC}\end{array}$} & \multirow[b]{2}{*}{$a=9.4475$} & \multicolumn{2}{|c|}{ Lattice parameters $(\AA, \mathrm{deg})$} & \multirow{2}{*}{$\begin{array}{l}\text { Atom } \\
\text { Sc1 }\end{array}$} & \multirow{2}{*}{$\begin{array}{l}\text { Wyckoff } \\
\text { site } \\
8 \mathrm{f}\end{array}$} & \multicolumn{3}{|c|}{$\begin{array}{l}\text { Atomic coordinates } \\
\text { (fractional) }\end{array}$} \\
\hline & & $b=5.3993$ & $c=13.3910$ & & & 0.00000 & 0.16212 & 0.10785 \\
\hline & $\alpha=90.0000$ & $\beta=90.0000$ & $\gamma=90.0000$ & Mo1 & $16 \mathrm{~h}$ & 0.16231 & 0.32956 & 0.57993 \\
\hline & & & & Ga1 & $4 c$ & 0.00000 & 0.72492 & 0.25000 \\
\hline & & & & $\mathrm{Ga} 2$ & $8 \mathrm{~g}$ & 0.77943 & 0.39171 & 0.25000 \\
\hline & & & & $\mathrm{C} 1$ & $4 b$ & 0.00000 & 0.50000 & 0.00000 \\
\hline & & & & $\mathrm{C} 2$ & $8 \mathrm{e}$ & 0.83271 & 0.00000 & 0.00000 \\
\hline \multirow[t]{3}{*}{$\left(\mathrm{Mo}_{2 / 3} \mathrm{Y}_{1 / 3}\right)_{2} \mathrm{GaC}$} & $a=9.6268$ & $b=5.5133$ & $c=13.7562$ & Y1 & $8 \mathrm{f}$ & 0.00000 & 0.16102 & 0.39215 \\
\hline & $\alpha=90.0000$ & $\beta=90.00000$ & $\gamma=90.0000$ & Mo1 & $8 \mathrm{f}$ & 0.16054 & 0.32772 & 0.57666 \\
\hline & & & & Gal & $4 c$ & 0.00000 & 0.67214 & 0.25000 \\
\hline
\end{tabular}




$\begin{array}{llllll}\mathrm{Ga} 2 & 8 \mathrm{~g} & 0.75335 & 0.41769 & 0.25000 \\ \mathrm{C} 1 & 4 \mathrm{~b} & 0.00000 & 0.50000 & 0.00000 \\ \mathrm{C} 2 & 8 \mathrm{e} & 0.82657 & 0.00000 & 0.00000\end{array}$

Principles of $\boldsymbol{i}$-MAX formation. Out of the 12 quaternary $i$-MAX phases considered theoretically in this work, four have been realized experimentally; $\left(\mathrm{Mo}_{2 / 3} \mathrm{Sc}_{1 / 3}\right)_{2} \mathrm{AlC},{ }^{39}$ $\left(\mathrm{Mo}_{2 / 3} \mathrm{Y}_{1 / 3}\right)_{2} \mathrm{AlC},{ }^{40}$ and herein $\left(\mathrm{Mo}_{2 / 3} \mathrm{Sc}_{1 / 3}\right)_{2} \mathrm{GaC}$ and $\left(\mathrm{Mo}_{2 / 3} \mathrm{Y}_{1 / 3}\right)_{2} \mathrm{GaC}$. Before making an educated guess of possible number of $i$-MAX family members, a fundamental understanding the origin of their formation would improve the potential for identification of materials that can be realized. The first step is to analyze the energy difference $\Delta \mathrm{E}$ between the hexagonal $P 6_{3} / m m c$ MAX phase structure (Figure 5a) and the orthorhombic $\mathrm{Cmcm} i$-MAX structure (Figure 5b) for an $i$-MAX composition, see Figure $5 \mathrm{c}$. The $i$-MAX structure is fully relaxed, while the lattice parameters and internal coordinates for the MAX phase structure is extrapolated from Vegards's law, using calculated structural parameters from relaxed (hypothetical) $\mathrm{Mo}_{2} A \mathrm{C}$ and $M_{2}^{2} A \mathrm{C}$. By forcing the Mo and $M^{2}$ atoms to be in one $M$-plane, the energy is drastically increased, more for Y-containing phases, and with a falling trend comparing the $A$-elements in different periods. These two observations can be related to the size of $M^{2}$ and $A$ (metallic and covalent radius depicted in Figure 7h). The large energy penalty found for $\mathrm{Y}$ can be related to a larger $M^{2}$ radius (1.80 $\AA$ metallic radius for $\mathrm{Y}$ ) as compared to Sc (1.62 §). The decrease in energy within group 13 and 14 can be correlated to an increase in size of $A$. 

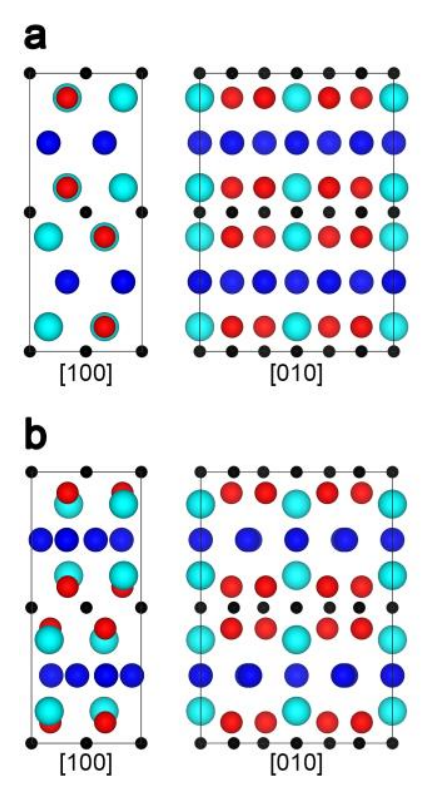

Mo Oscor Y A $\bullet$ C

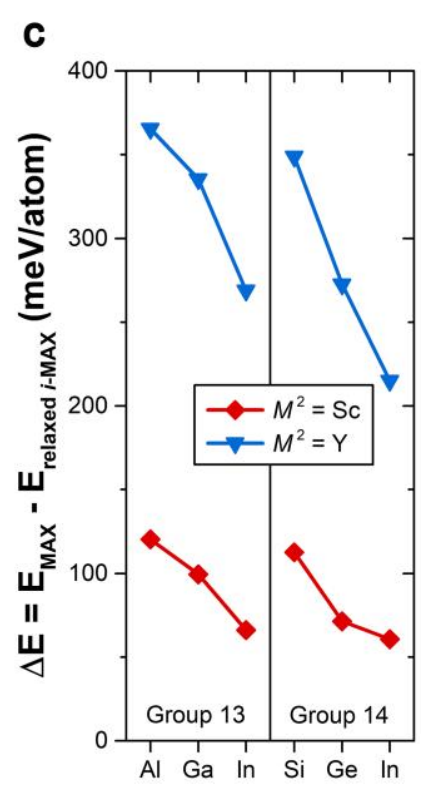

$A$ in $\left(\mathrm{Mo}_{2 / 3} M_{1 / 3}^{2}\right)_{2} A C$

Figure 5. Schematic representation of (a) the MAX phase structure and (b) the $i$-MAX structure at the $i$-MAX composition along the [100] and [010] zone axis. (c) Calculated energy difference $\triangle E$ between $\mathrm{MAX}$ and $i$-MAX structure for the $\left(\mathrm{Mo}_{2 / 3} \mathrm{Sc}_{1 / 3}\right)_{2} A \mathrm{C}$ (red diamonds) and $\left(\mathrm{Mo}_{2 / 3} \mathrm{Y}_{1 / 3}\right)_{2} A \mathrm{C}$ (blue triangles) composition as a function of A-group element. The lattice parameters and internal coordinates for the MAX phase structure at the $i$-MAX composition is obtained using Vegard's law and structural information from relaxed $\mathrm{Mo}_{2} A \mathrm{C}$ and $M_{2}^{2} A \mathrm{C}$.

Correlating between the choice of A-element and the $i$-MAX stability, a relevant parameter is the energy difference $\Delta \mathrm{E}$ between the MAX and $i$-MAX structure in Figure $5 \mathrm{c}$, showing a steady decrease with increase in size of $A$. Moreover, the size of $A$ also has an impact on the disorder temperature $T_{\text {disorder, }}$, as seen in Figure $1 \mathrm{~b}$, showing a decrease in $T_{\text {disorder }}$ with increase in size of $A$, further evaluated in bonding analysis presented below. This is most evident for group 13. It can be noted that the size difference between Sc (Y) and Mo is also reflected in larger $T_{\text {disorder }}$ for $\mathrm{Y}$-based compounds as compared to Sc-based ones. This is in line with previous findings for $i$-MAX phases, ${ }^{40}$ and correlates with the larger size difference between Mo and Y $(0.41 \AA)$ as compared to Sc $(0.23 \AA)$. Thus, a larger difference between Mo and $M^{2}$ results in increased cost in energy to form disorder which, in turn, will favor order. 
In the next step towards understanding the formation of these compounds we turn to the electronic properties and bonding characteristics. Total density of states (DOS) and projected crystal overlap Hamilton population (pCOHP) have been analyzed and are depicted in Figure 6, Figure S3 and S4. All compounds exhibit metallic properties due to the presence of states at the Fermi level $\left(E_{\mathrm{f}}\right)$. A common feature is the appearance of a local minima, a so-called pseudogap, in the immediate vicinity of $E_{\mathrm{f}}$, most noticeable for $\left(\mathrm{Mo}_{2 / 3} \mathrm{Y}_{1 / 3}\right)_{2} \mathrm{GaC}$. Such a gap is an indicator of stability through the clear separation of bonding and anti-bonding states, as initially outlined by Hume-Rothery. ${ }^{44}$ Furthermore, the atomic DOS in Figure 6c and e for $\left(\mathrm{Mo}_{2 / 3} \mathrm{Y}_{1 / 3}\right)_{2} \mathrm{GaC}$ and $\left(\mathrm{Mo}_{2 / 3} \mathrm{Y}_{1 / 3}\right)_{2} \mathrm{GaC}$, respectively, show states from about $-12 \mathrm{eV}$ to $-10.6 \mathrm{eV}$ (composed mainly of C-s and Mo- $p$ ), from -9 to $-6.5 \mathrm{eV}$ (mainly Ga-s), from -6.5 to $-3.4 \mathrm{eV}$ (C- $p$, Ga- $p$, Mo- $d$ and $M^{2}-d$ ), and from -3.5 to $0 \mathrm{eV}$ (mainly Ga- $p$, Mo- $d$ and $M^{2}-d$ ). Atomic DOS for the other $i$-MAX compounds are presented in Figure S3 and S4.

We further use the projected crystal overlap Hamilton population (pCOHP) analysis to understand the bonding nature of these compounds. pCOHP have been performed for the shortest bonds between and within layers in $\left(\mathrm{Mo}_{2 / 3} \mathrm{Sc}_{1 / 3}\right)_{2} \mathrm{GaC}$ and $\left(\mathrm{Mo}_{2 / 3} \mathrm{Y}_{1 / 3}\right)_{2} \mathrm{GaC}$ as displayed in Figure $6 \mathrm{~d}$ and $\mathrm{f}$. To facilitate interpretation and to preserve the analogy for crystal orbital overlap population (COOP) analysis, the results are here presented as $-\mathrm{pCOHP}$. From the pCOHP curves we find that most interactions below $E_{\mathrm{f}}$ are bonding with the exception of a small antibonding contribution for C-C just above $-4 \mathrm{eV}$ and for Mo-C from about -2 to $E_{\mathrm{f}}$. 

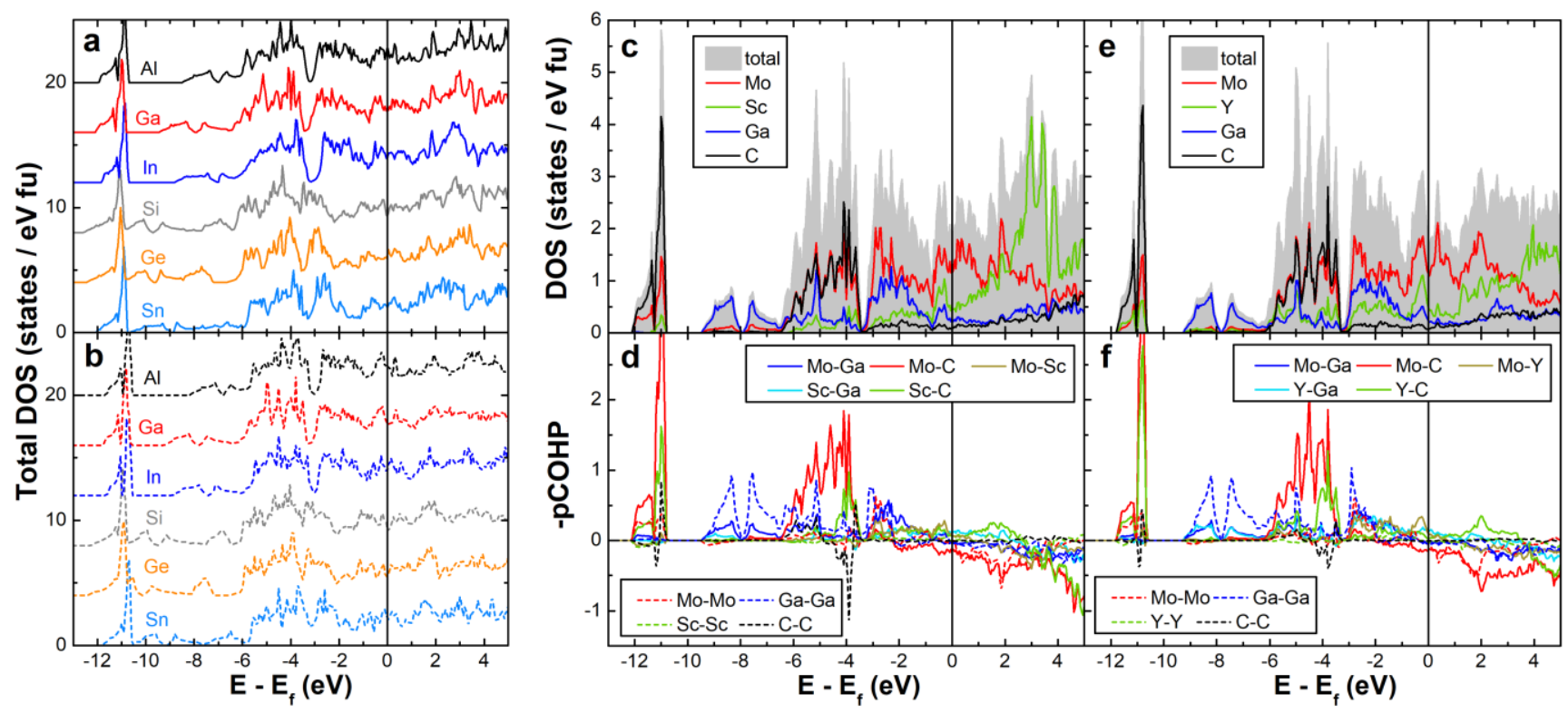

Figure 6. Calculated total density of states (DOS) for (a) $\left(\mathrm{Mo}_{2 / 3} \mathrm{Sc}_{1 / 3}\right)_{2} A \mathrm{C}$ and (b) $\left(\mathrm{Mo}_{2 / 3} \mathrm{Y}_{1 / 3}\right)_{2} A \mathrm{C}$ for $A=\mathrm{Al}, \mathrm{Ga}, \mathrm{In}, \mathrm{Si}, \mathrm{Ge}, \mathrm{Sn}$. Calculated total and atomic density of states and projected crystal overlap Hamilton population (pCOHP) analysis for (c,d) $\left(\mathrm{Mo}_{2 / 3} \mathrm{Sc}_{1 / 3}\right)_{2} \mathrm{GaC}$ and $(\mathrm{e}, \mathrm{f})\left(\mathrm{Mo}_{2 / 3} \mathrm{Y}_{1 / 3}\right)_{2} \mathrm{GaC}$ using the orthorhombic structure of space group $\mathrm{Cmcm}$.

From integrated pCOHP (IpCOHP) in Figure S5, it is possible to qualitatively estimate the strength of the interactions. For all compounds, Sc- as well as $\mathrm{Y}$-based, the Mo-C interaction is found to be the strongest, with IpCOHP of about $-3.5 \mathrm{eV}(-4.10 \leq \mathrm{IpCOHP} \leq 3.31 \mathrm{eV})$. Second strongest is $M^{2}-\mathrm{C}(-2.69 \leq \mathrm{IpCOHP} \leq-1.82 \mathrm{eV})$ with IpCOHP for $M^{2}=\mathrm{Y}$ being $\sim 0.5 \mathrm{eV}$ larger than for $M^{2}=\mathrm{Sc}$. This indicates stronger $\mathrm{Y}-\mathrm{C}$ bonds as compared to Sc-C bonds for herein considered $i$-MAX compounds.

Mo- $A$ interactions are overall stronger than $M^{2}-A$, most noticeably for $M^{2}=$ Sc. This can be correlated to structural differences for various $M^{2}$ and $A$ elements as presented in Figure 7, where we find that Mo- $A$ bonds are shorter compare to $M^{2}-A$. This is in contrast to smaller $M^{2}$ $A$ interlayer distance as compared to Mo- $A$, consistent with the projected distances shown in Figure 7f-g, but more clearly displayed from supporting cif-files. This result aligns with the possibility for selective etching of $M^{2}$ upon MXene derivation of $\mathrm{Mo}_{1.33} \mathrm{C}^{39}{ }^{45}$ Moreover, this 
also indicates that a combination of strong Mo- $A$ and weak $M^{2}-A$ is needed to enable selective etching of $M^{2}$.

From Figure 6 and Figure S5, we also notice that Mo- $A$ interaction tend to be strongest for $A$ from Period 4. This may be explained by Ga and Ge having the largest electronegativity, among considered $A$-elements, which in turn increases the covalency between the highly electronegative Mo and Ga or Ge as compared to the other $A$-elements. All in-plane monoelemental interactions are found to be relatively weak with $-0.75 \leq \mathrm{IpCOHP} \leq .0 .06 \mathrm{eV}$ with the exception for $A$ - $A$ when $A$ is from period $4(\mathrm{Ga}, \mathrm{Ge})$ and $5(\mathrm{In}, \mathrm{Sn})$. This relatively large $A$ $A$ IpCOHP, compared to $\mathrm{Al}$ and $\mathrm{Si}$, can be related to more active interaction of $s$, but also $p$ states of $A$ (compare panel (a) and (c) in Figure S3 and S4). The overall bonding is also correlated to the structural parameters, see Figure 7, which show overall larger lattices (volume) for the larger $\mathrm{Y}$, compared to Sc, further increasing with increasing radius of the $A$-element. Another feature is the interlayer distances between $M^{1}-M^{2}$ (Figure 7f) and $M^{2}-A$ (Figure 7g) as defined in Figure 6e, where $M^{2}-A$ in particular show strong correlation with the $A$-elemental size. Corresponding structural trends are also found for $i$-MAX in $C 2 / c$ structure as seen in Figure S6. 

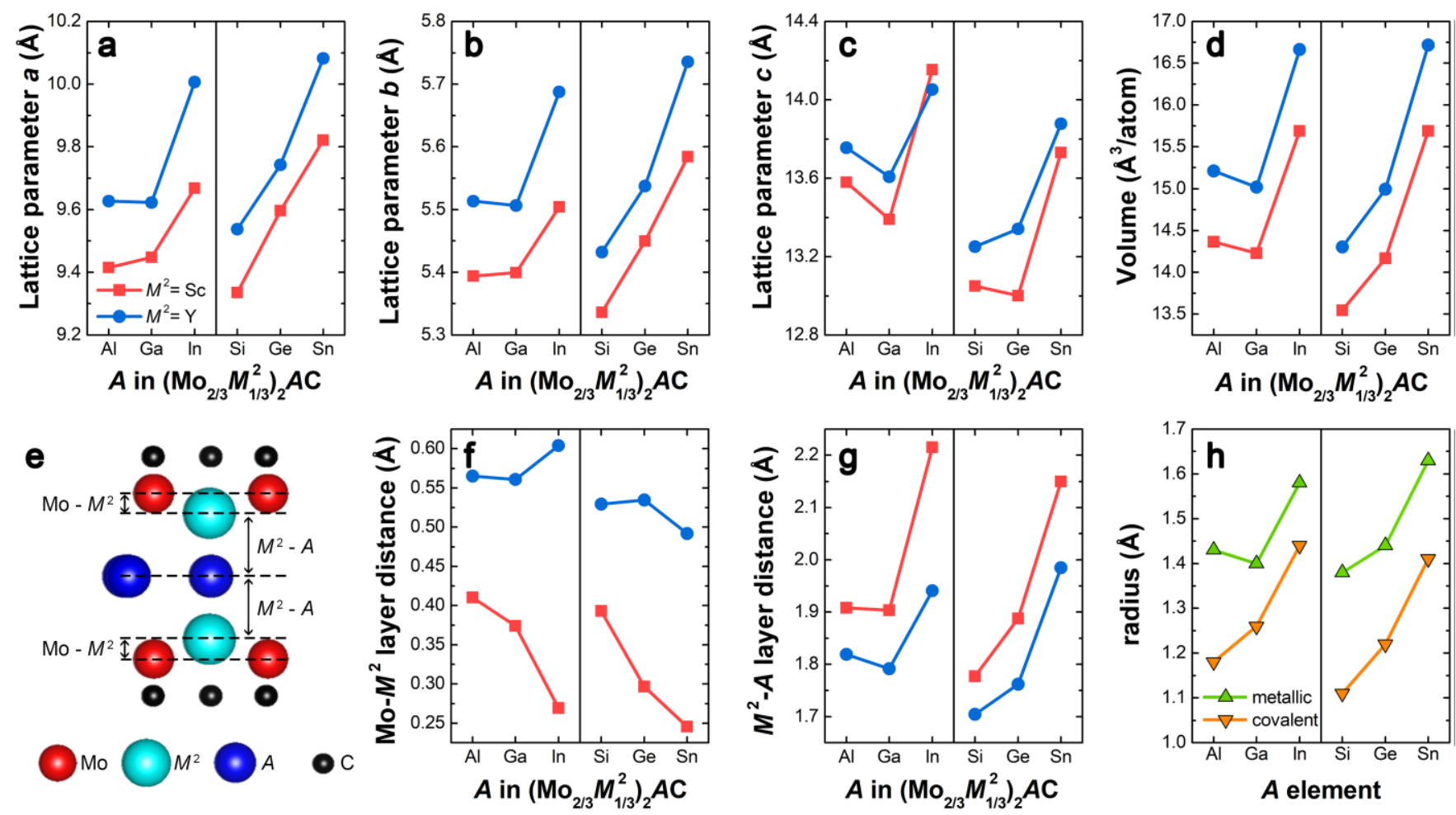

Figure 7. Calculated structural parameters for in-plane chemically-ordered $\left(\mathrm{Mo}_{2 / 3} \mathrm{Sc}_{1 / 3}\right)_{2} A \mathrm{C}$ (red squares) and $\left(\mathrm{Mo}_{2 / 3} \mathrm{Y}_{1 / 3}\right)_{2} A \mathrm{C}$ (blue circles) in $\mathrm{Cmcm}$ crystal structure as a function of $\mathrm{A}$ element. Lattice parameters (a) $a$, (b) $b$, and (c) $c$ with (d) corresponding calculated volume per atom. (e) Schematic representation of the C-M-A-M-C layers. Calculated interlayer distances for (f) Mo- $M^{2}$ and (g) $M^{2}-A$ as denoted in (e). (h) Metallic and covalent radius of A-group elements used herein.

From both DOS and pCOHP we conclude significant hybridization between Mo and C as well as $\mathrm{Sc}(\mathrm{Y})$ and $\mathrm{C}$ states below $E_{\mathrm{f}}$, suggesting the formation of strong covalent bonding between $\mathrm{Mo}-\mathrm{C}$ and $\mathrm{Sc}(\mathrm{Y})-\mathrm{C}$ atoms, respectively. For all Sc-based $i$-MAX compounds, there is an overall small shift of states to lower energies, with respect to the Y-based counterparts, which results in increased bonding energies. Most importantly, for Ge- and Sn-based $i$-MAX compounds, we find an increased population of Mo-Mo and $A-A$ interactions with an antibonding character as compared to Ga- and In-based dittos. This is also the true for $\mathrm{Al}$ and Si, but to a lesser extent. Thus, $A$-elements from Group 14 will contribute with additional 
electrons, as compared to Group 13, which have a negative influence on the $i$-MAX stability. The number of electrons contributing to bonding, non-bonding and antibonding interactions is a delicate balance, where too many electrons will lead to population of antibonding states with a negative impact on the phase formation, while too few electrons will not populate enough bonding states needed for a positive impact on the phase formation. We can speculate that Group 14 A-elements may form $i$-MAX phases if we decrease the number of electrons at the $M$-sites. However, we also need to take into consideration the size of the A-element itself and of outermost importance the size difference between $M^{1}$ and $M^{2}$, which should to have a large impact with $M^{2}$ (Sc, Y) being larger than $M^{1}$ (Mo). ${ }^{40}$

The report of a Kagomé-like Al lattice in $i$-MAX compounds in Ref. 40 was based on theoretical data with insufficient $\mathrm{Z}$ contrast of $\mathrm{Al}$ atoms at the time. The Kagomé-like lattice is a direct consequence of the $M^{2}$ displacement away from $M^{1}$ layer towards the $A$ layer, which rearrange the relatively loosely bonded $A$ atoms. ${ }^{40}$ A direct evidence of such lattice would require a plan-view HRSTEM image, which impose a rather challenging task in isolating the $A$ layer without destroying it (anti-MXene by etching $M_{2} \mathrm{C}$ sheets while $A$ is left untouched). Instead, we here take advantage of the higher $\mathrm{Z}$ contrast of $\mathrm{Ga}$, compared to $\mathrm{Al}$, as seen in sideview HRSTEM images and schematic representations in Figure 8a,c. When viewed along the along [110] zone axis the Ga layer show intensity variations which is related to different number of atoms along each column. The brighter spot, representing twice the Ga atoms compared to the less bright spot, are almost fully circular for $\left(\mathrm{Mo}_{2 / 3} \mathrm{Y}_{1 / 3}\right)_{2} \mathrm{GaC}$ while it is more of an ellipse form for $\left(\mathrm{Mo}_{2 / 3} \mathrm{Sc}_{1 / 3}\right)_{2} \mathrm{GaC}$. Overlaying the structural representation from theory on the HRSTEM supports this observation further. Within the simulated structural representation, we isolate the $A$ layer and look at a top-view, which clearly show the A-layer in-plane structure. As we here probe $i$-MAX compounds with various $A$ and $M^{2}$ we do see simulated differences within the $A$-lattice as function of $A$ and $M^{2}$, quantified as deviation from an ideal Kagomé 
lattice in terms of both $A$ - $A$ distance (Figure 8e) and bond angles within the layer (Figure 8f).

Definition of bond angles are given in Figure 8b,d.
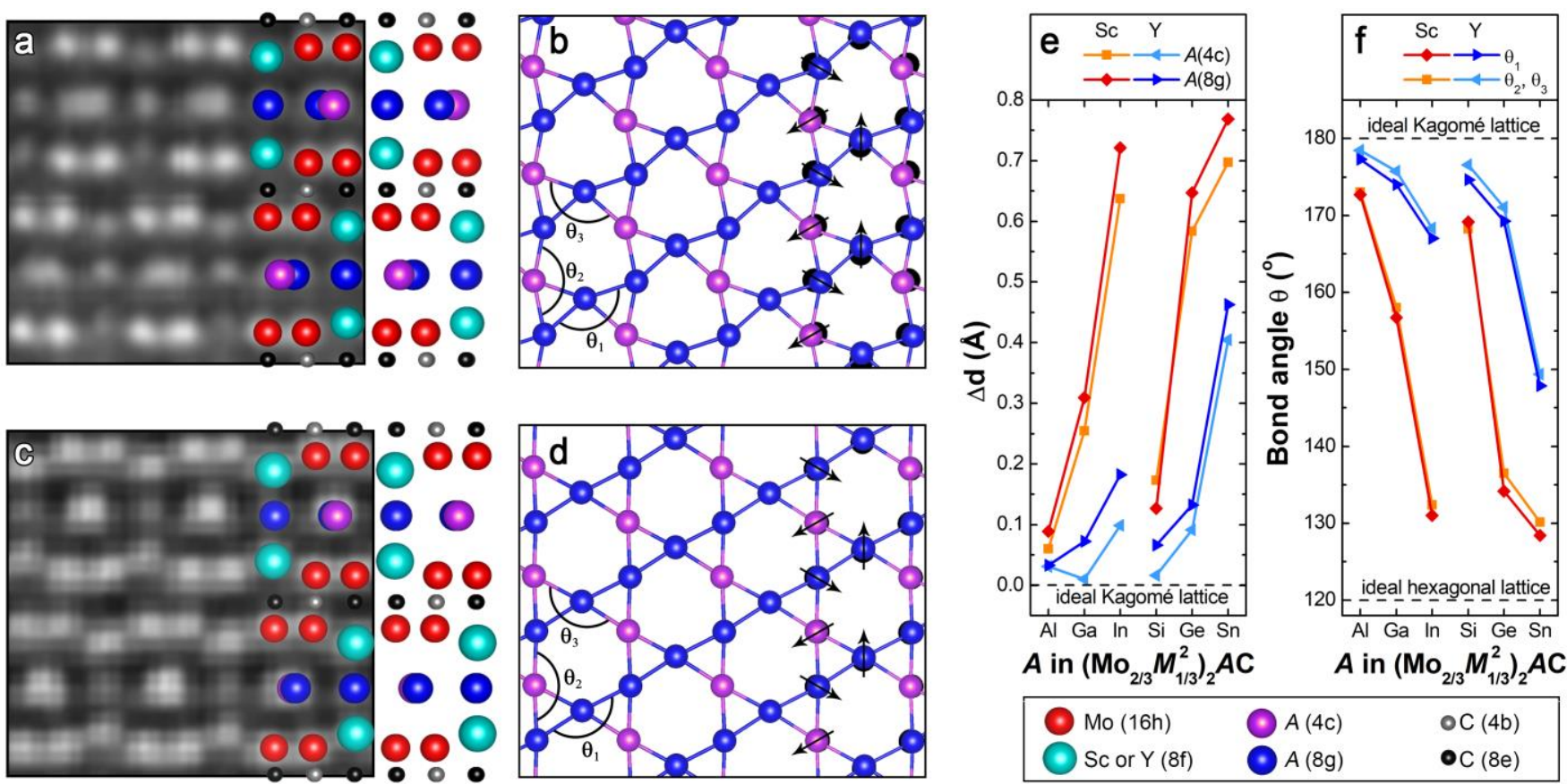

Figure 8. HRSTEM image and schematic representation along the [110] zone axis for (a) $\left(\mathrm{Mo}_{2 / 3} \mathrm{Sc}_{1 / 3}\right)_{2} \mathrm{GaC}$ and (c) $\left(\mathrm{Mo}_{2 / 3} \mathrm{Y}_{1 / 3}\right)_{2} \mathrm{GaC}$. Schematic representation of the Ga-layer along the [001] zone axis in (b) $\left(\mathrm{Mo}_{2 / 3} \mathrm{Sc}_{1 / 3}\right)_{2} \mathrm{GaC}$ and (d) $\left(\mathrm{Mo}_{2 / 3} \mathrm{Y}_{1 / 3}\right)_{2} \mathrm{GaC}$. (e) Bond angles $\theta_{\mathrm{i}}$ within the Ga layer and (f) displaced distance of the Ga atoms from an ideal Kagomé lattice as indicated in $(b, d)$.

The $i$-MAX compounds with an $A$-layer structure closest to an ideal Kagomé lattice have both large $M^{2}$, here Y, and small $A$, here either $\mathrm{Al}$ or Si. This is reflected in largest $T_{\text {disorder }}$ with $A$ from Period 3 (Al, Si), which in turn reflects the stability of the ordered $i$-MAX structure. Ga also displays a structure closely related to an ideal Kagomé lattice when $M^{2}=$ Y. Altogether, for $M^{2}=\mathrm{Sc}$ and with increasing size of $A$, the deviation away from an ideal Kagomé lattice is more pronounced as compared to $M^{2}=\mathrm{Y}$, even though they display similar trends. Also, the energy differences $\Delta E$ in Figure 5c does reflect the trends observed in Figure 7a,f. $\Delta E$ decreases with the size of $A$ as does the deviation away from an ideal Kagomé lattice. We note here that 
the trend for bond-angle deviation resembles the calculated $T_{\text {disorder }}$ in Figure $1 \mathrm{~b}$ and $\Delta E$ in Figure 5c. This indicates that as the size of the $A$ element increases, the driving force for chemical order decreases, at least in part due to limited space or limited energy gain for redistribution in the $A$-layer.

Altogether, the performed analysis can be summarized into the following key components for $i$-MAX formation: (i) a 2:1 ratio for $M^{1}: M^{2}$, (ii) an empirical size difference between $M^{1}$ and $M^{2}$ of at least $0.2 \AA$ where $M^{2}$ is larger than $M^{1}$, (iii) an electron population of ideally bonding orbitals only, where for the herein investigated $M$ elements (Mo and $\mathrm{Sc} / \mathrm{Y}$ ) a minimum population of anti-bonding orbitals is obtained for Group $13 A$-elements, and (iv) a smaller size of $A$ is beneficial. Of these criteria, the first three are believed to be most important. Applying criteria (i) and (ii) on possible combinations where $M=\mathrm{Sc}, \mathrm{Y}, \mathrm{Ti}, \mathrm{Zr}, \mathrm{Hf}, \mathrm{V}, \mathrm{Nb}, \mathrm{Ta}, \mathrm{Cr}, \mathrm{Mo}$, $\mathrm{W}$, and Mn, results in 22 possible $i$-MAX phases per $A$-element. Using the third criteria on traditional MAX phase A-elements Al, Si, P, S, Ga, Ge, As, Cd, In, Sn, Tl, Pb is a bit more complex, since we should ideally be aware of population, or not, of anti-bonding orbitals. We have shown herein that Group $13 A$-elements are found to be favored over Group 14 due to fewer electrons populating anti-bonding orbitals. Based on this result we can assume that $A$ elements from Group 15 (P and As) and 16 (S) will thus not favor formation of $i$-MAX phases. This criterion will, however, favor Group $12(\mathrm{Cd})$. The fourth criteria of having a small $A$, similar to or smaller than $\mathrm{Al}$ and $\mathrm{Ga}$, is fulfilled by $\mathrm{Al}, \mathrm{Ga}, \mathrm{Si}, \mathrm{Ge}, \mathrm{P}, \mathrm{As}$, and $\mathrm{S}$. Therefore, only $\mathrm{Al}$ and Ga fulfill both criteria (iii) and (iv), which combined with (i) and (ii) results in 44 possible and plausible $i$-MAX phases. Out of these, 9 have been synthesized so far. ${ }^{39,40,43,46}$

The implication of the analysis suggest that the family of $i$-MAX phases can be expanded, and that future unexplored compositions and properties can be expected. Moreover, the previous demonstration of controlled introduction of ordered divacancies in Mo1.33 C MXene resulted in one of the highest volumetric capacitance values reported for a $2 \mathrm{D}$ material at that 
time. ${ }^{39}$ Hence, in the light of $i$-MAX phases as parent materials for MXenes, the here identified rules can be used for realization of yet unexplored MXenes including elements beyond those used to date. The above results showing weaker $M^{2}-\mathrm{C}$ bonds as compared to the stronger Mo$\mathrm{C}$ can explain why selective etching of $\mathrm{Sc}$ and $\mathrm{Y}$ is possible when producing $\mathrm{Mo}_{1.33} \mathrm{C}$ MXene with ordered $M^{2}$-vacanices. ${ }^{39,}{ }^{45}$ Moreover, the stronger $\mathrm{Y}-\mathrm{C}$ bonds compared to Sc-C also demonstrates why use of different etching protocols to the parent $i$-MAX phase $\left(\mathrm{Mo}_{2 / 3} \mathrm{Y}_{1 / 3}\right)_{2} \mathrm{AlC}$ can result in either $\left(\mathrm{Mo}_{2 / 3} \mathrm{Y}_{1 / 3}\right)_{2} \mathrm{C}$ with in-plane elemental order through selective removal of $\mathrm{Al}$ atoms or $\mathrm{Mo}_{1.33} \mathrm{C}$ with ordered vacancies through selective removal of both $\mathrm{Al}$ and $\mathrm{Y}$ atoms. ${ }^{45}$

In a recent publication, the theoretical insights into exfoliation possibility of MAX phases to MXene shows a clear correlation between force constants, bond strengths, and static exfoliation energies of MAX phases to MXene. ${ }^{47}$ When the force constant of an $A$ atom contributed from the neighboring atoms is smaller, the exfoliation energy becomes smaller, thus making exfoliation of $A$ easier. Such analysis for the $i$-MAX phases requires an initial detailed analysis of the selected approach, due to the effect from etching of both $A$ and $M^{2}$. Furthermore, $i$-MAX phases recommended to be used for attempted MXene synthesis are all those predicted stable in this paper. This is motivated by the here identified weaker $M^{2}-\mathrm{C}$ bonds for all those $A$ elements, that may facilitate combined etching of $A$ elements beyond Al together with the $M^{2}$ element, and hence realization of a range of innovative MXenes. Moreover, this structural design on the atomic scale expand the concept of property-tailoring of $3 \mathrm{D}$ and $2 \mathrm{D}$ materials.

\section{CONCLUSIONS}

We have explored the origin of $i$-MAX formation through a combination of first-principles stability calculations and materials synthesis. Using $\left(\mathrm{Mo}_{2 / 3} \mathrm{Sc}_{1 / 3}\right)_{2} A \mathrm{C}$ and $\left(\mathrm{Mo}_{2 / 3} \mathrm{Y}_{1 / 3}\right)_{2} A \mathrm{C}$ as model systems and probing $A$ from Group 13 (Al, Ga, In) and 14 (Si, Ge, Sn), we predict seven $i$-MAX compounds to be thermodynamically stable, and estimate that five of those retain order 
also at typical bulk synthesis conditions. Materials synthesis of $\left(\mathrm{Mo}_{2 / 3} \mathrm{Sc}_{1 / 3}\right)_{2} \mathrm{GaC}$ and $\left(\mathrm{Mo}_{2 / 3} \mathrm{Y}_{1 / 3}\right)_{2} \mathrm{GaC}$ verified the theoretical predictions, and structural characterization using atomic-resolution STEM and XRD confirmed the in-plane chemical order within the $M$-layer, the Kagomé-like ordering of the $A$-layer, and an orthorhombic crystal structure of space group $\mathrm{Cmcm}$. Based on theoretical analysis of structure, bonding, and related stability, we suggest that the formation of $i$-MAX is favored for increasing size difference between the two metals, here Mo and $\mathrm{Sc}(\mathrm{Y})$, and with decreasing size of the A-element. For the $M$ elements herein, the Aelements from Group 13 (Al, Ga, In) are favored over Group 14 (Si, Ga, Sn) since antibonding interactions are being populated to a larger extent for the latter, which have a negative impact on the $i$-MAX formation. Using these guidelines, we expect further possible elemental substitution on both $M$ and $A$ sites in this family of chemically ordered quaternary laminates and suggest plausible $44 i$-MAX phases out of which 9 have been synthesized so far. This will undoubtedly allow for exploration of advantageous properties. Moreover, based on $i$-MAX phases as parent materials for MXenes, we also expect that the range of MXene compositions will be expanded.

\section{METHOD}

Computational details. We use the non-spin polarized generalized gradient approximation (GGA), parameterized by Perdew-Burke-Ernzerhof (PBE) ${ }^{48}$ as implemented in the Vienna ab-initio simulation package (VASP) ${ }^{49-51}$ using the projector augmented wave method, ${ }^{52,53}$ with an energy cutoff of $400 \mathrm{eV}$. The Brillouin zone is sampled using the Monkhorst-Pack scheme. ${ }^{54}$ All structures were relaxed until the forces on each ion converged to below $10^{-4} \mathrm{eV} \AA^{-1}$. Using DFT, we investigated the thermodynamic stability of $\left(M_{2 / 3}^{1} M_{1 / 3}^{2}\right)_{2} \mathrm{AC}$ phases at $0 \mathrm{~K}$ with respect to decomposition into any combination of competing phases as well as dynamic (phonon) stability. Here, we use a linear optimization procedure 
based on the simplex method, to identify the set of most competing phases, the equilibrium simplex, under the constraint of a fixed $i$-MAX stoichiometry. ${ }^{55,56} \mathrm{We}$ do not consider temperature-dependent effects, e.g., lattice vibrations, as such contribution from a phase, significant or not, tend to be cancelled out in the free energy term. ${ }^{42}$ This approach has been proven to work exceptionally well for MAX, $o$-MAX, and $i$-MAX phases, ${ }^{5,6,37,38,40,56}$. The compound's stability is quantified in terms of formation enthalpy $\Delta H_{c p}$ by comparing its energy to the energy of the equilibrium simplex,

$$
\Delta H_{c p}=E(\text { compound })-E(\text { equilibrium simplex }) \text {. }
$$

For $\Delta H_{c p}<0$ the compound is considered stable, while for $\Delta H_{c p}>0$ it is considered to be not stable or at best metastable. Our selection of competing phases includes all known elemental, binary, ternary, and quaternary phases from the elements that form the stoichiometry under investigation. We also include hypothetical phases, based on compounds that exist in similar systems and/or with neighboring elements in the Periodic table, as competing phases. A complete list of competing phases considered herein are found in Table S2.

Chemically-disordered candidate structures, e.g., solid-solution alloys of $M^{1}$ and $M^{2}$ on the $M$ sublattice, were modelled using the special quasi-random structures (SQS) method ${ }^{57}$ Energy convergence with respect to the size of the super cell was performed, showing that a cell size of $6 \times 3 \times 1 M_{2} A X$ unit cells or larger display an energy within $2 \mathrm{meV}$ per atom, while lattice parameters $a$ and $c$ are within $0.3 \%$. Further information related to super cell convergence in terms of calculated energies and lattice parameters are given in Fig. S1 in Ref. 40.

When $T \neq 0 \mathrm{~K}$, the Gibbs free energy $\Delta G_{c p}^{\text {disorder }}$ for a disordered phase is approximated using

$$
\Delta G_{c p}^{\text {disorder }}=\Delta H_{c p}^{\text {disorder }}-T \Delta S
$$

where the entropic contribution $\Delta S$, assuming an ideal solution of $M^{1}$ and $M^{2}$ on the $M$-sites, is given by

$$
\Delta S=-2 \mathrm{k}_{B}[z \ln (z)+(1-z) \ln (1-z)],
$$


where $\mathrm{z}$ is the $M^{2}$ concentration.

By using Eq. 2 and 3, a disorder temperature $T_{\text {disorder }}$ can be calculated according to

$$
T_{\text {disorder }}=\frac{\Delta H_{c p}^{\text {disorder }}-\Delta H_{c p}^{\text {order }}}{\Delta S}
$$

for which $\Delta G_{c p}^{\text {disorder }}[T]=\Delta H_{c p}^{\text {order }}$ is fulfilled and hence give an estimate above which temperature chemical disorder is expected.

Schematics were produced with VESTA. ${ }^{58}$

Synthesis. Polycrystalline $\left(\mathrm{Mo}_{2 / 3} \mathrm{Sc}_{1 / 3}\right)_{2} \mathrm{GaC}$ and $\left(\mathrm{Mo}_{2 / 3} \mathrm{Y}_{1 / 3}\right)_{2} \mathrm{GaC}$ samples were synthesized by solid-state reaction from elemental powders; graphite (99.9995\%) Alfa Aesar, Mo (99.99\%) Sigma-Aldrich, Y (99.5\%) Sigma-Aldrich, Sc (99.99\%) Stanford Advanced Materials. For Ga, metal pellets (99.99999\%, Mining and Chemical Products Limited) of about $7 \mathrm{~mm}$ diameter weighing $\sim 1 \mathrm{~g}$ were used, which were further mechanically cleaved into smaller pieces of about $1 \mathrm{~mm}$ in size. To obtain $\left(\mathrm{Mo}_{2 / 3} \mathrm{Sc}_{1 / 3}\right)_{2} \mathrm{GaC}$, elemental Mo:Sc:C powders of a 4:2:3 stoichiometry were mechanically mixed in an agate mortar, then placed in an alumina crucible, together with $\mathrm{Ga}$ pellets in stoichiometric ratio of 4:2:3:3 for Mo:Sc:Ga:C respectively, and then heated at $10{ }^{\circ} \mathrm{C}$ per minute up to $1400{ }^{\circ} \mathrm{C}$ under $5 \mathrm{sccm}$ Ar flow, and finally being held at $1400{ }^{\circ} \mathrm{C}$ for $10 \mathrm{~h}$. To obtain $\left(\mathrm{Mo}_{2 / 3} \mathrm{Y}_{1 / 3}\right)_{2} \mathrm{GaC}$, elemental Mo:Y:C powders of a 4:2:3 stoichiometry were mixed in an agate mortar, and then placed in an alumina crucible together with Ga pellets in stoichiometric ratio of 4:2:3:3 for Mo:Y:Ga:C respectively, heated with $10{ }^{\circ} \mathrm{C}$ per min up to $1300{ }^{\circ} \mathrm{C}$ under $5 \mathrm{sccm}$ Ar flow, and finally being held at $1300{ }^{\circ} \mathrm{C}$ for $10 \mathrm{~h}$. The samples were cooled down to room temperature in the furnace, and the obtained powder was further crushed in an agate mortar.

Multiple samples in the temperature range of $1300{ }^{\circ} \mathrm{C}-1500{ }^{\circ} \mathrm{C}$ were attempted where the most optimal temperature for each material system is given above. The deposition time was 
chosen to be $10 \mathrm{~h}$ based on previous experimental synthesis of $\left(\mathrm{Mo}_{2 / 3} \mathrm{Y}_{1 / 3}\right)_{2} \mathrm{AlC}$, ${ }^{40}$ which worked well also for $\left(\mathrm{Mo}_{2 / 3} \mathrm{Sc}_{1 / 3}\right)_{2} \mathrm{GaC}$ and $\left(\mathrm{Mo}_{2 / 3} \mathrm{Y}_{1 / 3}\right)_{2} \mathrm{GaC}$.

Characterization. XRD measurements were performed on a PANalytical X'Pert powder diffractometer equipped with a $\mathrm{Cu}-\mathrm{K}_{\alpha}$ radiation source. For these measurements, a graded Bragg-Brentano HD with a $1 / 4^{\circ}$ divergent and $1 / 2^{\circ}$ anti-scattered slits, and a $5 \mathrm{~mm}$ anti-scatter slit together with a Soller slit (with an opening rad. of 0.04), in the incident beam side and the diffracted beam side were utilized, respectively. A continuous scan from $5^{\circ}$ to $120^{\circ}$ was performed on the sample using a step size of $0.008^{\circ}$ with a $40 \mathrm{~s}$ time per step. Scanning transmission electron microscopy (STEM) combined with high angle annular dark field imaging (STEM-HAADF) and energy dispersive X-ray (EDX) analysis with a Super-X EDX detector was performed in the double-corrected Linköping FEI Titan ${ }^{3} 60-300$, operated at 300 $\mathrm{kV}$. The specimens were prepared by embedding the ground-mixed powder in a $\mathrm{Cu}$ grid with C film.

\section{ASSOCIATED CONTENT}

Supporting Information. The Supporting Information is available free of charge on the ACS Publications website at DOI:

Additional density of states and bonding information for all 12 considered $i$-MAX phases; structural trends for the monoclinic $C 2 / c$ structure; identified set of most competing phases for each $i$-MAX phase; complete list of considered competing phases (PDF)

Structural files for all 12 considered $i$-MAX phases (cif)

\section{AUTHOR INFORMATION}

\section{Corresponding Authors}

*E-mail: martin.dahlqvist@liu.se

*E-mail: johanna.rosen@liu.se 


\section{ORCHID}

$\begin{array}{ll}\text { Martin Dahlqvist } & 0000-0001-5036-2833 \\ \text { Andrejs Petruhins } & 0000-0002-9745-5380 \\ \text { Jun Lu } & 0000-0003-2754-6962 \\ \text { Lars Hultman } & 0000-0002-2837-3656 \\ \text { Johanna Rosen } & 0000-0002-5173-6726\end{array}$

Author Contributions

The manuscript was written through contributions of all authors. All authors have given approval to the final version of the manuscript.

\section{ACKNOWLEDGMENT}

J.R. and L.H. acknowledge support from the Knut and Alice Wallenberg (KAW) Foundation for a Scholar Grant, a Fellowship Grant, Project funding (KAW 2015.0043), and for support to the Linköping Ultra Electron Microscopy Laboratory. The Swedish Research council is gratefully acknowledged through Project 621-2012-4425, 621-2013-4018, and 642-2013-8020. The calculations were carried out using supercomputer resources provided by the Swedish National Infrastructure for Computing (SNIC) at the National Supercomputer Centre (NSC), the High Performance Computing Center North (HPC2N), and the PDC Center for High Performance Computing. 


\section{REFERENCES}

1. Wilmer, C. E.; Leaf, M.; Lee, C. Y.; Farha, O. K.; Hauser, B. G.; Hupp, J. T.; Snurr, R. Q., Large-Scale Screening of Hypothetical Metal-Organic Frameworks. Nat. Chem. 2012, 4, 83-89.

2. Kumar, H.; Frey, N. C.; Dong, L.; Anasori, B.; Gogotsi, Y.; Shenoy, V. B., Tunable Magnetism and Transport Properties in Nitride MXenes. ACS Nano 2017, 11, 76487655.

3. Zakutayev, A.; Zhang, X.; Nagaraja, A.; Yu, L.; Lany, S.; Mason, T. O.; Ginley, D. S.; Zunger, A., Theoretical Prediction and Experimental Realization of New Stable Inorganic Materials Using the Inverse Design Approach. J. Am. Chem. Soc. 2013, 135, 10048-10054.

4. Wu, Y.; Lazic, P.; Hautier, G.; Persson, K.; Ceder, G., First Principles High Throughput Screening of Oxynitrides for Water-Splitting Photocatalysts. Energ. Environ. Sci. 2013, $6,157-168$.

5. Ingason, A. S.; Petruhins, A.; Dahlqvist, M.; Magnus, F.; Mockute, A.; Alling, B.; Hultman, L.; Abrikosov, I. A.; Persson, P. O. Å.; Rosen, J., A Nanolaminated Magnetic Phase: $\mathrm{Mn}_{2} \mathrm{GaC}$. Mater. Res. Lett. 2014, 2, 89-93.

6. Eklund, P.; Dahlqvist, M.; Tengstrand, O.; Hultman, L.; Lu, J.; Nedfors, N.; Jansson, U.; Rosén, J., Discovery of the Ternary Nanolaminated Compound $\mathrm{Nb}_{2} \mathrm{GeC}$ by a Systematic Theoretical-Experimental Approach. Phys. Rev. Lett. 2012, 109, 035502.

7. Barsoum, M. W., The $\mathrm{M}_{\mathrm{n}+1} \mathrm{AX}_{\mathrm{n}}$ Phases: A New Class of Solids; Thermodynamically Stable Nanolaminates. Prog. Solid State Chem. 2000, 28, 201-281.

8. Eklund, P.; Beckers, M.; Jansson, U.; Högberg, H.; Hultman, L., The $\mathrm{M}_{\mathrm{n}+1} \mathrm{AX}_{\mathrm{n}}$ Phases: Materials Science and Thin-Film Processing. Thin Solid Films 2010, 518, 1851-1878.

9. Lapauw, T.; Lambrinou, K.; Cabioc'h, T.; Halim, J.; Lu, J.; Pesach, A.; Rivin, O.; Ozeri, O.; Caspi, E. N.; Hultman, L.; Eklund, P.; Rosén, J.; Barsoum, M. W.; Vleugels, J., Synthesis of the New MAX Phase Zr $\mathrm{r}_{2} \mathrm{AlC}$. J. Eur. Ceram. Soc. 2016, 36, 1847-1853.

10. Dahlqvist, M.; Ingason, A. S.; Alling, B.; Magnus, F.; Thore, A.; Petruhins, A.; Mockute, A.; Arnalds, U. B.; Sahlberg, M.; Hjörvarsson, B.; Abrikosov, I. A.; Rosen, J., Magnetically Driven Anisotropic Structural Changes in the Atomic Laminate $\mathrm{Mn}_{2} \mathrm{GaC}$. Phys. Rev. B 2016, 93, 014410.

11. Ingason, A. S.; Pálsson, G. K.; Dahlqvist, M.; Rosen, J., Long-Range Antiferromagnetic Order in Epitaxial $\mathrm{Mn}_{2} \mathrm{GaC}$ Thin Films from Neutron Reflectometry. Phys. Rev. B 2016, 94, 024416.

12. Barsoum, M. W.; El-Raghy, T., The MAX Phases: Unique New Carbide and Nitride Materials - Ternary Ceramics Turn out to Be Surprisingly Soft and Machinable, yet Also Heat-Tolerant, Strong and Lightweight. Am. Scientist 2001, 89, 334-343.

13. Barsoum, M. W.; Zhen, T.; Kalidindi, S. R.; Radovic, M.; Murugaiah, A., Fully Reversible, Dislocation-Based Compressive Deformation of $\mathrm{Ti}_{3} \mathrm{SiC}_{2}$ to $1 \mathrm{Gpa}$. Nat. Mater. 2003, 2, 107-111.

14. Farle, A.-S.; Kwakernaak, C.; van der Zwaag, S.; Sloof, W. G., A Conceptual Study into the Potential of $\mathrm{M}_{\mathrm{n}+1} \mathrm{AX}_{\mathrm{n}}$-Phase Ceramics for Self-Healing of Crack Damage. $J$. Eur. Ceram. Soc. 2015, 35, 37-45.

15. Sloof, W. G.; Pei, R.; McDonald, S. A.; Fife, J. L.; Shen, L.; Boatemaa, L.; Farle, A.-S.; Yan, K.; Zhang, X.; Zwaag, S. v. d.; Lee, P. D.; Withers, P. J., Repeated Crack Healing in MAX-Phase Ceramics Revealed by 4D in Situ Synchrotron X-Ray Tomographic Microscopy. Sci. Rep. 2016, 6, 23040. 
16. Mockute, A.; Dahlqvist, M.; Emmerlich, J.; Hultman, L.; Schneider, J. M.; Persson, P. O. Å.; Rosen, J., Synthesis and Ab Initio Calculations of Nanolaminated (Cr,Mn) $)_{2} \mathrm{AlC}$ Compounds. Phys. Rev. B 2013, 87, 094113.

17. Ingason, A. S.; Mockute, A.; Dahlqvist, M.; Magnus, F.; Olafsson, S.; Arnalds, U. B.; Alling, B.; Abrikosov, I. A.; Hjörvarsson, B.; Persson, P. O. Å.; Rosen, J., Magnetic Self-Organized Atomic Laminate from First Principles and Thin Film Synthesis. Phys. Rev. Lett. 2013, 110, 195502.

18. Meshkian, R.; Ingason, A. S.; Arnalds, U. B.; Magnus, F.; Lu, J.; Rosen, J., A Magnetic Atomic Laminate from Thin Film Synthesis: $\left(\mathrm{Mo}_{0.5} \mathrm{Mn}_{0.5}\right)_{2} \mathrm{GaC}$. APL Mater. 2015, 3, 076102.

19. Naguib, M.; Kurtoglu, M.; Presser, V.; Lu, J.; Niu, J.; Heon, M.; Hultman, L.; Gogotsi, Y.; Barsoum, M. W., Two-Dimensional Nanocrystals Produced by Exfoliation of $\mathrm{Ti}_{3} \mathrm{AlC}_{2}$. Adv. Mater. 2011, 23, 4248-4253.

20. Naguib, M.; Mochalin, V. N.; Barsoum, M. W.; Gogotsi, Y., 25th Anniversary Article: MXenes: A New Family of Two-Dimensional Materials. Adv. Mater. 2014, 26, $992-$ 1005.

21. Anasori, B.; Lukatskaya, M. R.; Gogotsi, Y., 2D Metal Carbides and Nitrides (MXenes) for Energy Storage. Nat. Rev. Mater. 2017, 2, 16098.

22. Shahzad, F.; Alhabeb, M.; Hatter, C. B.; Anasori, B.; Man Hong, S.; Koo, C. M.; Gogotsi, Y., Electromagnetic Interference Shielding with 2D Transition Metal Carbides (MXenes). Science 2016, 353, 1137-1140.

23. Cabioch, T.; Eklund, P.; Mauchamp, V.; Jaouen, M.; Barsoum, M. W., Tailoring of the Thermal Expansion of $\mathrm{Cr}_{2}\left(\mathrm{Al}_{\mathrm{x}}, \mathrm{Ge}_{1-\mathrm{x}}\right) \mathrm{C}$ Phases. J. Eur. Ceram. Soc. 2013, 33, 897-904.

24. Meng, F. L.; Zhou, Y. C.; Wang, J. Y., Strengthening of $\mathrm{Ti}_{2} \mathrm{AlC}$ by Substituting Ti with V. Scripta Mater. 2005, 53, 1369-1372.

25. Tao, Q.; Salikhov, R.; Mockute, A.; Lu, J.; Farle, M.; Wiedwald, U.; Rosen, J., Thin Film Synthesis and Characterization of a Chemically Ordered Magnetic Nanolaminate (V,Mn) ${ }_{3} \mathrm{GaC}_{2}$. APL Mater. 2016, 4, 086109.

26. Mockute, A.; Lu, J.; Moon, E. J.; Yan, M.; Anasori, B.; May, S. J.; Barsoum, M. W.; Rosen, J., Solid Solubility and Magnetism Upon Mn Incorporation in the Bulk Ternary Carbides $\mathrm{Cr}_{2} \mathrm{AlC}$ and $\mathrm{Cr}_{2} \mathrm{GaC}$. Mater. Res. Lett. 2014, 3, 16-22.

27. Lapauw, T.; Tytko, D.; Vanmeensel, K.; Huang, S.; Choi, P.-P.; Raabe, D.; Caspi, E. a. N.; Ozeri, O.; to Baben, M.; Schneider, J. M.; Lambrinou, K.; Vleugels, J., $\left(\mathrm{Nb}_{\mathrm{x}}, \mathrm{Zr}_{1-}\right.$ x) ${ }_{4} \mathrm{AlC}_{3}$ MAX Phase Solid Solutions: Processing, Mechanical Properties, and Density Functional Theory Calculations. Inorg. Chem. 2016, 55, 5445-5452.

28. Manoun, B.; Saxena, S. K.; Hug, G.; Ganguly, A.; Hoffman, E. N.; Barsoum, M. W., Synthesis and Compressibility of $\mathrm{Ti}_{3}\left(\mathrm{Al}, \mathrm{Sn}_{0.2}\right) \mathrm{C}_{2}$ and $\mathrm{Ti}_{3} \mathrm{Al}\left(\mathrm{C}_{0.5}, \mathrm{~N}_{0.5}\right)_{2}$. J. Appl. Phys. 2007, 101, 113523-113527.

29. Horlait, D.; Grasso, S.; Chroneos, A.; Lee, W. E., Attempts to Synthesise Quaternary MAX Phases $(\mathrm{Zr}, \mathrm{M})_{2}$ alc and $\mathrm{Zr}_{2}(\mathrm{Al}, \mathrm{A}) \mathrm{C}$ as a Way to Approach $\mathrm{Zr}_{2} \mathrm{AlC}$. Mater. Res. Lett. 2016, 4, 137-144.

30. Horlait, D.; Middleburgh, S. C.; Chroneos, A.; Lee, W. E., Synthesis and DFT Investigation of New Bismuth-Containing MAX Phases. Sci. Rep. 2016, 6, 18829.

31. Cabioch, T.; Eklund, P.; Mauchamp, V.; Jaouen, M., Structural Investigation of Substoichiometry and Solid Solution Effects in $\mathrm{Ti}_{2} \mathrm{Al}\left(\mathrm{C}_{\mathrm{x}}, \mathrm{N}_{1-\mathrm{x}}\right)_{\mathrm{y}}$ Compounds. J. Eur. Ceram. Soc. 2012, 32, 1803-1811.

32. Saltas, V.; Horlait, D.; Sgourou, E. N.; Vallianatos, F.; Chroneos, A., Modelling Solid Solutions with Cluster Expansion, Special Quasirandom Structures, and Thermodynamic Approaches. Appl. Phys. Rev. 2017, 4, 041301. 
33. Ashton, M.; Hennig, R. G.; Broderick, S. R.; Rajan, K.; Sinnott, S. B., Computational Discovery of Stable $M_{2} A X$ Phases. Phys. Rev. B 2016, 94, 054116.

34. Rosen, J.; Persson, P. O. Å.; Ionescu, M.; Kondyurin, A.; McKenzie, D. R.; Bilek, M. M. M., Oxygen Incorporation in $\mathrm{Ti}_{2} \mathrm{AlC}$ Thin Films. Appl. Phys. Lett. 2008, 92 , 064102-064103.

35. Nechiche, M.; Gauthier-Brunet, V.; Mauchamp, V.; Joulain, A.; Cabioc'h, T.; Milhet, X.; Chartier, P.; Dubois, S., Synthesis and Characterization of a New (Ti1$\left.{ }_{\varepsilon}, \mathrm{Cu}_{\varepsilon}\right)_{3}(\mathrm{Al}, \mathrm{Cu}) \mathrm{C}_{2} \mathrm{MAX}$ Phase Solid Solution. J. Eur. Ceram. Soc. 2017, $37,459$.

36. Liu, Z.; Zheng, L.; Sun, L.; Qian, Y.; Wang, J.; Li, M., $\left(\mathrm{Cr}_{2 / 3} \mathrm{Ti}_{1 / 3}\right)_{3} \mathrm{AlC}_{2}$ and $\left(\mathrm{Cr}_{5 / 8} \mathrm{Ti}_{3 / 8}\right)_{4} \mathrm{AlC}_{3}$ : New MAX-Phase Compounds in Ti-Cr-Al-C System. J. Am. Ceram. Soc. 2014, 97, 67-69.

37. Anasori, B.; Dahlqvist, M.; Halim, J.; Moon, E. J.; Lu, J.; Hosler, B. C.; Caspi, E. N.; May, S. J.; Hultman, L.; Eklund, P.; Rosén, J.; Barsoum, M. W., Experimental and Theoretical Characterization of Ordered MAX Phases $\mathrm{Mo}_{2} \mathrm{TiAlC}_{2}$ and $\mathrm{Mo}_{2} \mathrm{Ti}_{2} \mathrm{AlC}_{3} . J$. Appl. Phys. 2015, 118, 094304.

38. Meshkian, R.; Tao, Q.; Dahlqvist, M.; Lu, J.; Hultman, L.; Rosen, J., Theoretical Stability and Materials Synthesis of a Chemically Ordered MAX Phase, $\mathrm{Mo}_{2} \mathrm{ScAlC}_{2}$, and Its Two-Dimensional Derivate $\mathrm{Mo}_{2} \mathrm{ScC}_{2}$ MXene. Acta Mater. 2017, 125, 476-480.

39. Tao, Q.; Dahlqvist, M.; Lu, J.; Kota, S.; Meshkian, R.; Halim, J.; Palisaitis, J.; Hultman, L.; Barsoum, M. W.; Persson, P. O. Å.; Rosen, J., Two-Dimensional Mo1.33C MXene with Divacancy Ordering Prepared from Parent 3D Laminate with in-Plane Chemical Ordering. Nat. Commun. 2017, 8, 14949.

40. Dahlqvist, M.; Lu, J.; Meshkian, R.; Tao, Q.; Hultman, L.; Rosen, J., Prediction and Synthesis of a Family of Atomic Laminate Phases with Kagomé-Like and in-Plane Chemical Ordering. Sci. Adv. 2017, 3, e1700642.

41. Thore, A.; Rosen, J., An Investigation of the in-Plane Chemically Ordered Atomic Laminates $\left(\mathrm{Mo}_{2 / 3} \mathrm{Sc}_{1 / 3}\right)_{2} \mathrm{AlC}$ and $\left(\mathrm{Mo}_{2 / 3} \mathrm{Y}_{1 / 3}\right)_{2} \mathrm{AlC}$ from First Principles. Phys Chem Chem Phys 2017, 19, 21595-21603.

42. Thore, A.; Dahlqvist, M.; Alling, B.; Rosén, J., Temperature Dependent Phase Stability of Nanolaminated Ternaries from First-Principles Calculations. Comput. Mater. Sci. 2014, 91, 251-257.

43. Lu, J.; Thore, A.; Meshkian, R.; Tao, Q.; Hultman, L.; Rosen, J., Theoretical and Experimental Exploration of a Novel in-Plane Chemically-Ordered $\left(\mathrm{Cr}_{2 / 3} M_{1 / 3}\right)_{2} \mathrm{AlC}$ iMAX Phase with $M=$ Sc and Y. Cryst. Growth Des. 2017, 17, 5704-5711.

44. Hume-Rothery, W.; Smallman, R. E.; Haworth, C. W., The Structure of Metals and Alloys. The Institute of Metals: London, 1969.

45. Persson, I.; Ghazaly, A. e.; Tao, Q.; Halim, J.; Kota, S.; Darakchieva, V.; Palisaitis, J.; Barsoum, M. W.; Rosen, J.; Persson, P. O. A., Tailoring Structure, Composition, and Energy Storage Properties of MXenes from Selective Etching of in-Plane, Chemically Ordered MAX Phases. Small 2018, 14, 1703676.

46. Meshkian, R.; Dahlqvist, M.; Lu, J.; Wickman, B.; Halim, J.; Thörnberg, J.; Tao, Q.; Li, S.; Intikhab, S.; Snyder, J.; Barsoum, M. W.; Yildizhan, M.; Palisaitis, J.; Hultman, L.; Persson, P. O. Å.; Rosen, J., W-Based Atomic Laminates and Their 2D Derivative $\mathrm{W}_{1.33} \mathrm{C}$ MXene with Vacancy Ordering. Adv. Mater. 2018, 30, 1706409.

47. Khazaei, M.; Ranjbar, A.; Esfarjani, K.; Bogdanovski, D.; Dronskowski, R.; Yunoki, S., Insights into Exfoliation Possibility of MAX Phases to MXenes. Phys Chem Chem Phys 2018, 20, 8579-8592.

48. Perdew, J. P.; Burke, K.; Ernzerhof, M., Generalized Gradient Approximation Made Simple. Phys. Rev. Lett. 1996, 77, 3865-3868. 
49. Kresse, G.; Hafner, J., Ab Initio Molecular Dynamics for Liquid Metals. Phys. Rev. B 1993, 47, 558-561.

50. Kresse, G.; Furthmüller, J., Efficiency of Ab-Initio Total Energy Calculations for Metals and Semiconductors Using a Plane-Wave Basis Set. Comput. Mater. Sci. 1996, 6, 1550 .

51. Kresse, G.; Furthmüller, J., Efficient Iterative Schemes for Ab Initio Total-Energy Calculations Using a Plane-Wave Basis Set. Phys. Rev. B 1996, 54, 11169-11186.

52. Blöchl, P. E., Projector Augmented-Wave Method. Phys. Rev. B 1994, 50, 17953 17979.

53. Kresse, G.; Joubert, D., From Ultrasoft Pseudopotentials to the Projector AugmentedWave Method. Phys. Rev. B 1999, 59, 1758-1775.

54. Monkhorst, H. J.; Pack, J. D., Special Points for Brillouin-Zone Integrations. Phys. Rev. $B$ 1976, 13, 5188-5192.

55. Dahlqvist, M.; Alling, B.; Abrikosov, I. A.; Rosén, J., Phase Stability of $\mathrm{Ti}_{2} \mathrm{AlC}$ Upon Oxygen Incorporation: A First-Principles Investigation. Phys. Rev. B 2010, 81, 024111.

56. Dahlqvist, M.; Alling, B.; Rosén, J., Stability Trends of MAX Phases from First Principles. Phys. Rev. B 2010, 81, 220102.

57. Zunger, A.; Wei, S. H.; Ferreira, L. G.; Bernard, J. E., Special Quasirandom Structures. Phys. Rev. Lett. 1990, 65, 353-356.

58. Momma, K.; Izumi, F., VESTA 3 for Three-Dimensional Visualization of Crystal, Volumetric and Morphology Data. J. Appl. Crystallogr. 2011, 44, 1272-1276. 